\title{
Teleconsultation for pediatric patients with type 1 diabetes mellitus during the COVID-19 pandemic: experience of a university hospital in Brazil
}

Yasmin Eugênia Santana ( $\square$ yasmineugenia17@hotmail.com )

Universidade de São Paulo

Thais Milioni Luciano

Universidade de São Paulo

Ana Carolina Maia Teodózio

Universidade de São Paulo

Amanda Maria Barradas Monteiro Santana

Universidade de São Paulo

Letícia Rodrigues Ramos

Universidade de São Paulo

Marília Oliveira Barbosa Alves

Universidade de São Paulo

Luiza Siqueira Rabelo Bastos

Universidade de São Paulo

Brena de Sá Cardoso

Universidade de São Paulo

Mônica Freire Stecchini

Universidade de São Paulo

Rodrigo José Custódio

Universidade de São Paulo

Raphael Del Roio Liberatore Liberatore Junior

Universidade de São Paulo

Research Article

Keywords: diabetes, teleconsultation, COVID-19

Posted Date: June 22nd, 2021

DOI: https://doi.org/10.21203/rs.3.rs-603528/v1 
License: (c) (i) This work is licensed under a Creative Commons Attribution 4.0 International License. Read Full License

Version of Record: A version of this preprint was published at Jornal de Pediatria on March 1st, 2022. See the published version at https://doi.org/10.1016/j.jped.2022.02.001. 


\section{Abstract}

Introduction: The SARS-CoV-2 pandemic expanded rapidly around the world in 2020 and health services needed to be reconfigured to meet the new demand and ensure the care of patients with chronic diseases. For patients with diabetes mellitus, the teleconsultation stood out as a tool for clinical management in this period.

Objective: Evaluate the impact of teleconsultation on glycemic control and prevention of acute complications related to diabetes mellitus in children and adolescents treated in a reference hospital during the COVID-19 pandemic in 2020.

Method: Descriptive study of data from pediatric diabetic patients who received teleconsultation between April and September 2020.

Results: During this period, 143 diabetic patients were evaluated, with a median of 3.4 teleconsultations per patient in the studied period; requiring adjustment of insulin doses in $84.6 \%$ of cases. The hospital admission rate was $8,4 \%$ due to diabetic decompensation. The metabolic control ( $\mathrm{HbA} 1 \mathrm{c})$ became worsen in $46 \%$ of the sample and improved in $37 \%$.

Conclusion: The teleconsultation promoted health care for patients with diabetes mellitus during the COVID-19 pandemic, but was not able to guarantee adequate glycemic control.

\section{Introduction}

The outbreak of severe acute respiratory syndrome resulting from infection with the new coronavirus (SARS-CoV-2) started in China in late 2019 spread rapidly across the world and was officially recognized as a pandemic by the World Health Organization in March $2020^{1}$. Until at the time of writing this manuscript (March / 2021), there are 117.764.619 infected with the coronavirus in the world and more than 2 million deaths ${ }^{2}$. The United States leads in number of infected and dead, with Brazil in second place in number of dead and in third place in number of infected in the world ${ }^{2}$. The first confirmed case of coronavirus infection in Brazil occurred on February 26, 2020, in the city of São Paulo ${ }^{3}$. Ribeirão Preto had its first confirmed case on March 21, 2020 and, until March 9, 2021, it has 55,857 confirmed cases, according to an epidemiological bulletin released on March $10,2021^{5}$.

According to the Brazilian Diabetes Society, it is estimated that in Brazil 7.6 per 100 thousand inhabitants under the age of 15 are carriers of type 1 diabetes mellitus (T1DM), with an increase in this incidence being observed in the last decades, particularly in children under 5 years ${ }^{9}$. T1DM is a chronic disease, requiring multidisciplinary follow-up and regular medical assistance. The pediatric endocrinology scientific committee of the Brazilian Society of Pediatrics published a warning note on April 7, 2020 on T1DM and COVID-19 in pediatrics, not recommending elective consultations to avoid the risk of contamination and encouraged contact with the medical team by phone, text messages and e-mails ${ }^{10}$. 
The WHO defines telemedicine as "the provision of health services, where distance is a critical factor, by all health professionals, using information and communication technologies to exchange valid information for the diagnosis, treatment and prevention of diseases and injuries, for research and evaluation, and for the continuing education of health care providers, all in the interest of promoting the health of individuals and their communities " 8 .

National and local determinations authorized the use of telemedicine, allowed the pediatric endocrinology team from to reduce outpatients' activities to what was strictly necessary.

Teleconsultation had never been carried out on a large scale and it is not known what was the impact on the clinical control of patients. In this context, this study aimed to assess the impact of teleconsultation on clinical follow-up and metabolic control in pediatric diabetic patients during the COVID-19 pandemic.

\section{Materials And Methods}

This is a cross-sectional observational study on teleconsultations of diabetic patients under follow up at a pediatric hospital in Ribeirão Preto, Brazil (Hospital das Clínicas, Ribeirão Preto Medical School, University of São Paulo - HC-FMRP-USP) between April to September 2020, during the COVID-19 pandemic.

Data were collected from the review of the exchanged messages between the medical team and patients or their families. The teleconsultation consisted of those that included: sending glycemic controls to the conference by the assistant team; checking the insulin doses in use; verification of the presence of symptoms of diabetes decompensation; adequacy of insulin doses. The number of telephone calls in the period; the adjustment of insulin doses; the need for hospitalization due to diabetes decompensation and the comparison of glycosylated hemoglobin values before and during the COVID-19 pandemic were evaluated in this study.

This work was submitted to the Research Ethics Committee and approved via Plataforma Brasil[ (No. 4,220,266).

\section{Results}

There were 280 T1DM pediatric patients under follow up during the period of study. 143 patients received contacts for teleconsultation during the period from April to September 2020.

The epidemiological characteristics of the 143 study participants are summarized in Table 1. Females (57\%) and adolescents (59\%) were the majority of the patients evaluated. From those 143 patients, 13 were diagnosed during the period of study and $30 \%$ had less than 2 years of T1DM. 


\begin{tabular}{|ll|}
\hline Characteristics & Number of patients $(\mathbf{n}=143)$ \\
\hline Sex & $82(57 \%)$ \\
\hline - Female & $61(43 \%)$ \\
\hline Age & \\
\hline - Infant (0-2 years) & $4(3 \%)$ \\
\hline - Early Childhood (2-7 years) & $17(12 \%)$ \\
\hline - Middle Childhood (7-11 years) & $37(26 \%)$ \\
\hline - Adolescence (11-20 years) & $85(59 \%)$ \\
\hline Diagnosis time of T1DM & \\
\hline - New cases & $13(9 \%)$ \\
\hline - 0-2 years of diagnosis & $44(30 \%)$ \\
\hline - 2-5 years of diagnosis & $34(24 \%)$ \\
\hline - 5-10 years of diagnosis & $32(22 \%)$ \\
\hline - More than 10 years of diagnosis & $11(15 \%)$ \\
\hline
\end{tabular}

Table 1 - Description of pediatric diabetic patients followed by teleconsultation from April to September 2020.

During the period of study, 493 teleconsultations were carried out for the 143 pediatric diabetic patients included in the study, with an average of 3.4 teleconsultations per patient in the evaluated period (5 months).

The period for teleconsultations was, on average, 40 hours per week, totalizing 1040 hours.

Insulin doses adjustments were done in $84.6 \%$ of the calls. From the 143 patients evaluated, $8.4 \%$ needed hospitalization due to the decompensation of the disease (12 cases). There was no need for more than one hospital stay in the period.

The glycosylated hemoglobin ( $\mathrm{HbA1c}$ ) values were compared during the year of 2020 with the values of 2019. Results of $\mathrm{HbA} 1 \mathrm{c}$ reduced in more than $0.5 \%$ were considered as improved; those who presented an increase in glycosylated hemoglobin value greater than $0.5 \%$ were considered as worsen; results difference of less than $0.5 \%$ were considered as no change. Among the patients, $46 \%$ showed 
worsen, $37 \%$ showed improved and $17 \%$ showed no change of HbA1c during the COVID-19 pandemic. Therapeutic target ${ }^{11}(\mathrm{HbA} 1 \mathrm{c}<7.5 \%)$ was achieved in $30 \%$ of the patients.

The average of glycosylated hemoglobin values before the pandemic were compared with the results during the COVID-19 pandemic in 2020. The average of HbA1c before the pandemic was 9.2\%; on the other hand, the average of $\mathrm{HbA} 1 \mathrm{c}$ during the pandemic was $9.7 \%$.

\section{Discussion}

The teleconsultation in the diabetic population was already an important strategy of folow up even before the current pandemic. During COVID-19 pandemic, this way of care must be considered and evaluated in order to guarantee the best possible health care for patients.

A recent publication by the Barbara Davis Center reports success in glycemic control of new cases of $\mathrm{T}_{1 \mathrm{DM}}{ }^{15}$. Patients diagnosed during the pandemic had their education in diabetes and management of insulin doses made exclusively by telemedicine after hospital discharge. A combination of e-mail, video calls and telephone calls were used to provide guidance, check blood glucose levels and adjust the medication of these patients, achieving good glycemic control.

In the 143 patients, we made adjustment of insulin doses, review of the injection technique and resolution of doubts related to disease. Even with more frequent contacts, $\mathrm{HbA} 1 \mathrm{c}$ values became worst in $46 \%$ of patients during the COVID-19 pandemic.

A systematic review found that diabetic patients monitored by telemedicine showed a small, reduction in glycosylated hemoglobin compared to patients who were exclusively monitored by conventional medical care $(-0.31 \%, p<0.001)^{13}$.

A study conducted in Turkey to assess the impact of teleconsultations by a multidisciplinary team (doctor, nurse, nutritionist and psychologist) observed that patients showed an improvement on glycosylated hemoglobin $(-0.85 \%, p<0.01)$, but the contacts were made on daily base $\mathrm{b}^{13}$.

The metabolic control before 2020 was already not adequate. In the group of patients followed in this study, the more frequent contact between the hospital staff and the families did not improve the metabolic control.

We speculate if weekly contacts or even daily contacts would improve metabolic control. It is important to remember that our patients are from low income and educate status, with a lot of social issues.

The worsen values and average of $\mathrm{HbA} 1 \mathrm{c}$ during telemedicine assistance in this study demonstrate that this new form of patient care needs further studies to ensure adequate clinical management of patients in the future. 


\section{Conclusion}

Due to the need for a decrease in the number of in-person outpatient consultations, in order to guarantee an effective social distance due to the pandemic by COVID-19, telemedicine provided guidance and assistance to patients. This new form of medical care provided health care for pediatric diabetic patients followed by our pediatric endocrinology team. Our experience with teleconsultation demonstrated a predominance of worsen $\mathrm{HbA1c}$ control in patients. Further studies are needed to assess the real impact of this new form of care in the clinical follow-up of patients with chronic diseases, such as those with T1DM in the pediatric age group.

\section{Declarations}

Ethics approval and consent to participate: This study was approved by Research Ethics Committee of HC-FRMP-USP via Plataforma Brasil@ (No. 4.220.266).

Consent for publication: Not applicable.

Availability of data and materials: All data generated or analysed during this study are included in this published article.

Competing interests: The authors declare that they have no competing interests.

Funding: Own funding.

Authors' contributions: Not applicable.

Acknowledgements: Not applicable.

Authors' information (optional): Not applicable.

\section{Abbreviations}

COVID-19: disease caused by the new coronavirus SARS-Cov-2.

HbA1c: glycosylated hemoglobin.

HC-FMRP-USP: Hospital das Clínicas, Ribeirão Preto Medical School, University of São Paulo.

T1DM: type 1 (one) of diabetes mellitus.

\section{References}

1- Mahaese E. Covid-19: WHO declares pandemic because of alarming levels of spread, severity, and inaction. BMJ. 2020 Mar; 368: m1036. https // doi.org / 10.1136 / bmj.m1036 
2- Johns Hopkins University and medicine. Coronavirus Resource Center. 2020. Accessed on March 10, 2021. Available at: <http://coronavirus.jhu.edu/map.html>

3- Brazil. Ministry of Health. Coronavirus panel. 2020. Consulted on March 10, 2021. Available at: <http: //covid.saúde.gov.br>

4- São Paulo. Health Secretariat of São Paulo. Distribution of population, cases and deaths. 2020. Consulted on March 10, 2021. Available at: <http://seade.gov.br/coronavirus>

5- Ribeirão Preto City Hall. Health Secretariat - Epidemiological Surveillance Division. Coronavirus epidemiological bulletin (COVID19).

6- Federal Council of Medicine. CFM Official Letter No. 1756/2020 - COJUR. 19 Mar 2020.

7- Law n 13,989, of April 15, 2020. Diario Oficial da União. April 16, 2020, edition 73, section 1, page 1.

8- Telemedicine - Opportunities and developments in member states (Internet), second ed, Geneva, Switzerland: WHO press; 2010. Available at:

<https://www.who.int/goe/publications/goe_telemedicine_2010.pdf>

9- Brazilian Diabetes Society. Guidelines of the Brazilian Diabetes Society 2019-2020. Part 1, p. 14. Available at: <https://www.diabetes.org.br/profissional/images/DIRETRIZES-COMPLETA-2019-2020.pdf>

10- Brazilian Society of Pediatrics. Alert note: Diabetes mellitus and COVID-19 in Pediatrics. Published on April 7, 2020. Available at: https://www.sbp.com.br/fileadmin/user_upload/22440b-NA_-

Diabetes_Mellitus_e_COVID-19_em_Pediatria.pdf

11- Brazilian Diabetes Society. Guidelines of the Brazilian Diabetes Society 2014-2015. Update on glycated hemoglobin: clinical manifestations.

12- Flodgren $\mathrm{G}$, et al. Interactive telemedicine: effects on professional practice and health care outcomes. Cochrane Database of Systematic Reviews 2015, Issue 9. Art. No .: CD002098. DOI: 10.1002 / 14651858.CD002098.pub2

13- Timpel P., et al. Mapping the evidence on the effectiveness of telemedicine interventions in diabetes, dyslipidemia, and hypertension: an umbrella review of systematic reviews and meta-analyzes. J Med Internet Res. 2020 Mar 18; 22 (3): e16791. DOI: 10.2196 / 16791

14- Doger E., et al. Effect of telehealth system on glycemic control in children and adolescents with type 1 diabetes. J Clin Res Pediatr Endocrinol 2019; 11 (1): 70-75. DOI: 10.4274 / jcrpe.galenos.2018.2018.0017

15. Satish K. Garg, David Rodbard, Irl B. Hirsch and Gregory P. Forlenza. Diabetes Technology \& Therapeutics. June 2020. 431-439. DOI: 10.1089 / day.2020.0161 


\section{Supplementary Files}

This is a list of supplementary files associated with this preprint. Click to download.

- table1.docx 